\title{
Educational Reform and Practice of Experimental Course in Architectural Environment and Equipment Engineering Profession
}

\author{
Wang Xiao-lu \\ Jinling Institute of Technology \\ Mechanical Electrical Engineering Institute \\ Nanjing, China \\ wang156189@163.com
}

\author{
Huang Da-yu \\ Jinling Institute of Technology \\ Mechanical Electrical Engineering Institute \\ Nanjing, China \\ huang189@163.com
}

\begin{abstract}
Based on the present existing problems of experimental course in Architectural Environment and Equipment Engineering, the paper conducts the reform and innovation from the teaching mode, case teaching, interactive teaching etc. and introduces the scene experience type teaching mode combined with the research in the aspects of practical experience in recent years. The article constructs the "theoretical scene type teaching and practical experience and extracurricular interest team" trinity experiment teaching system, forms the teaching characteristics of basic knowledge reinforcement and experimental process are acted as guide, improves the students ability for analyzing and solving problems using the learned knowledge, and lay a foundation to further improve the quality and effectiveness of education.
\end{abstract}

Keywords-experimental teaching; scene experience; educational reform

\section{PREFACE}

The experimental teaching is an important component of the professional courses education in Architectural Environment and Equipment Engineering, and it is a method for students to obtain knowledge and skills, it not only can cultivate students' scientific research ability, innovative spirit, and enhance scientific literacy of students, but also can test and verify books theory knowledge, consolidate and expand the content of the learned courses, what's more, students' engineering consciousness and innovation ability is developed through the experiment teaching, meanwhile, it is an important task of the teaching reform. In recent years, many experts engaged in practice experimental teaching have done a lot teaching reforms and practices, and they have made many achievements ${ }^{[1-4]}$.Combined with the characteristics of the experimental courses, the paper conducts a large number of exploration researches in allusion to the application of scene type teaching mode in the practice teaching link, put forwards the "theory scene type teaching and practical experience and extracurricular interest team (the second classroom)" trinity practical teaching system mainly from "strengthen experimental teaching and related professional knowledge" connection, increase the fusion of practice and professional knowledge, and actively carry out extracurricular scientific research activities etc. aspects, and it greatly strengthen the students' training of practical innovation ability, the above aspects are discussed and analyzed in the article, and they provide the new teaching methods and ideas for experimental course teaching for the sake of peer common share.

\section{PROFESSIONAL CHARACTERISTICS AND EXISTING PROBLEMS OF EXPERIMENTAL TEACHING}

Architectural Environment and Equipment Engineering Profession mainly foster the special environment development of senior engineering technical personnel engaged in indoor environment equipment system and building public facilities design, installation debugging, operation management and the sectors of national economy. Undergraduate course graduate have design, installation, commissioning operation ability of HVAC, air-conditioning, gas supply, architectural water supply and drainage and other public system, and building heat energy supply system. The students of the specialty mainly study the basic theory and knowledge of architectural physical environment and environmental control system, and accept the basic training for the design, debugging and operation management and other areas of building equipment system, and they initially have the work ability. Therefore, the professional demands of student's manipulative capacity, equipment operation management ability is high, the success of the experimental course teaching not only provides the basic theory knowledge for students to study related professional course, but also lay the necessary theoretical basis for students to engaged in engineering design, construction installation, equipment development etc. in the future ${ }^{[1-2]}$.

With the education reform especially the expansion of university enrollment, it also appears some problems in experimental course teaching process, such as: more teaching material contents, less experimental classes, less equipment, etc. Contemporary college students obtain information approach is increasing, how to coordinate the relationship of the teaching content and self-study content, and to guide students how to effectively use the class and extracurricular time, etc. And the relationship of the theory teaching problems is all placed in front of us. 
III. THE APPLICATION RESEARCH OF SCENE EXPERIENCE TEACHING MODE IN EXPERIMENTAL TEACHING

\section{A. The scene experience teaching mode}

Scene experience teaching refers to the teachers actively create all kinds of situations in teaching, and guide students experience in various processes from passive to active, from dependent to independent, from receptive to creative, and learn to avoid, defeat and transform negative emotion and false acquaintance, and develop, enjoy and utilize positive emotion and correct understanding in experience, to make the students feel fully the joy and pleasure embodied in the teaching activities, and then achieve the purpose of promoting students' self- development. Situational experience type teaching is a kind of educations for emphasizing the interactive contact between knowledge and learning subject, it pays attention to the deepening participation of learners, highlight two-way exchange and communication of people, students and teaching material, not importune unification understanding but respect individual differences, each has the gain ${ }^{[3-9]}$.

Compared with the traditional teaching mode, the characteristics of the situation experience type teaching are as follows: At first, it emphasizes the students' subjectivity. In scene experience type teaching, the teachers are dominant, and the students are subject. Teachers create learning conditions and opportunities for students, communication and interaction with students, lead them to form the correct cognition. Students will not be the teaching audience no longer, passively accept the inspiring content, but utilize thought, emotion and feeling to form the profound understanding on the object through their own initiative experience the teachers create situations in the teachers' creating the situation; The second, it pays attention to the improvement of students' comprehensive quality. Students allodium utilize their thought and emotion to experience, feeling, and complete the learning process through the communication and interaction with teachers and students in creating teaching scene. The teaching method not only attach importance to knowledge learning, but also pay attention to the improvement of students' comprehensive quality, such as: learning capacity, innovative thinking ability, communication skills, etc. The third, it attaches great importance to the communication and interaction of teachers and students. The interaction is a vital link in the learning process between teacher and students. In the experience process, the existing question, not perceived knowledge, even some wrong cognition can be really solved and corrected only by means of the discussion and communication, meanwhile, it can deepen the understanding of the object in interaction process ${ }^{[6]}$.

In the experimental course, students who are located in lively and simulate scene will have a deep impression in situational experience type teaching through their own thinking, experience and behavior training, which then translate into a habit, even attain to the extent of the life-long benefit. Therefore, situational experience teaching has strong function in the experimental teaching courses. First of all, creating various scene experience process, that is to make full use of various education resources, and make up for the shortage of teaching material contents; Secondly, it is helpful to strengthen the students' power of thought, enlighten mental, reach to the purpose of practice teaching, enhance the practical ability, cultivate team combat spirit, and satisfy the needs of society.

\section{B. The application of situational experience type teaching mode in experimental teaching}

The experimental teaching is an important link of the university curriculum, one of its main purpose is verifying and enhancing the students' to comprehend and grasp the booklore, strengthening students' comprehensive ability of utilizing the course knowledge, meanwhile, it synthetically trains their experimental skills and methods, develops the ability of analyzing and resolving complex problem. In the meantime, it makes students deepen the understanding of the teaching content, cultivate students' ability of utilizing the equipment and research problems in the measurement process using experimental methods, such as: the similarities and differences of the instruments, the formulation of test strategy, the post processing of measurement data, etc. According to years of practice and grope, we also made some try in experimental teaching, traditional experiments often follows experimental steps to "the teacher explained, the test demonstrated, the students did practical operation", as the teacher completed the test principle and steps, the students quickly proceed experiment operations for the time is limited and the lack of understanding on experimental principle and objective, thus there exists a situation of individual students have a smattering of knowledge and blindingly finish the experiment.

In view of the above mention, "teaching - feedback model" of the division of responsibility of instructor and experimental teachers is carried out through the introduce of the situational experience type teaching method, modern network platform is used while teacher speak of the related experiment contents in class, it can play the actual operation video, make full use of the image, create typical scenes, stir up students' learning mood, combine the cognitive activities with emotional activities, emphatically inform students the application of the experiment, that is to beforehand study the experimental objective and content, and reach to the purpose of strengthening knowledge in advance, therefore, the students would have some perceptual knowledge and imagination of experiment in their minds; And then, the instructor and teacher are both present in the actual experiments, they timely resolve the problems in experimental process, the instructor summarizes the experiment and explain announcements of data processing as the experimental operation is ended. Through the above adjustment, which can guarantee the effect and quality of the experiment, cultivate students' pragmatic spirit and independent ability, and also improve their observation, analysis, problem-solving skills. 


\section{Case teaching}

Case teaching is a set of teaching methods of which the teacher help learners to achieve a specific learning goals by regarding teaching case as the carrier in class. In the modern education, the teaching method is used of law education in Harvard University, and it obtained an excellent teaching efficiency, and then, it gradually become a standard teaching mode of law, medicine, business, etc. but its application to the teaching of specialized course is less in science and engineering academy ${ }^{[3]}$.

Whether the case teaching is success or not, whose key lies in if the case can stimulate students' thinking, arouse their interest in learning, effectively improve the teaching effect, therefore, the choice of cases, content arrangement and logical organization is so important, meanwhile, the integration of information and the ability of covering knowledge is vital for students to master relevant knowledge, combined with the case teaching experience of course team for experimental course in Architectural Environment and Equipment Engineering for many years, the matters of attention in the case teaching is shared as follows.

One of the case teaching principle: the case should have the integrative logical structure. Whichever case organization should move around a same knowledge center, whether your case is to solve what kind of the problems, and how many branches does it has, the messy units can always wear into a line merely, you will found that it has solved a typical problem of air-conditioning, ventilation or heating suchlike the logic structure from the head to the end of the line.

The second principle of case teaching: the case should be close to the engineering practice. After all, the major pays attention to the application of architectural environment and equipment, for example, if we choose the case which is closely related to the life in the teaching process, we will be close to students in a psychological level, and got approval. Thus, in the next explanation and learning process, students will be full of desire for knowledge, and willing to accept, to learn, to understand, even to search relevant content after class, consequently stimulate their conscientious initiative. As the measurement experiment of smoke ventilation pipe are explained, we timely put in the case of mine ventilation, stimulate the students' learning interest, meanwhile, it is helpful to the understanding of the content.

The third principle of case teaching: the case teaching methods are flexible, students are the theme, teacher's role is guiding and steering in case teaching, they elicit case through the appropriate questions and organize the students to carry on thinking, discussion and interpretation, in the meanwhile, the appropriate encourage and question way should be adopted, the application effects are obvious for students to use hortative and heuristic teaching methods, and the teacher should make a summarize and comment on student's speech and case radiation content, and then, they also put forward some key questions to let students to think after class, the students hand in their tasks in the form of paper or assignment, finally, it can achieve the purpose of the case teaching, and strengthen the their understanding to the content, application and absorption.

\section{The application of network technology platform}

Interactive teaching mode is a kind of open and participant teaching model, the model round learners as a center, and make full use of various information channels and advanced teaching means, it is a kind of wide and diversified teaching mode for absorbing the knowledge. Interactive teaching mode follows the theory of psychology intrinsic motivation. It can makes learners increase desire and interest for study, so the students can consciously overcome difficulties, and obtain pleasure, satisfy, confidence, achievement and value from the learning process, such as: retrieval, lecture, production etc. ${ }^{[4]}$.

In recent years, the interactive pattern teaching is introduced into the experimental teaching, we center on the related experimental subject, release seminar topics on the internet, and students make up a interest team, the conferential and open teaching mode effectively strengthen the knowledge communication and information feedback between teacher and students, it make full use of multimedia network technology ${ }^{[5]}$, increase experimental teaching information, frontier dynamic and latest achievements, concentrate and improve the efficiency of the curriculum, the model provide for students, with opportunity of problemsolving, free thinking and communication, and it encourages students to ask questions, inspires the innovation, develops their ideas, mobilizes their learning enthusiasm, makes students obtain knowledge and ability more derivatively and diversity.

\section{CONCLUDING REMARKS}

The paper proceed a large number of reform and try through the scene experience type teaching, case teaching, the application of network technology and so on, the experimental teaching of architectural environment and equipment engineering has formed a complete teaching system, abundant content and aggressive teacher team, the article constructs the "theoretical scene type teaching + practical experience + extracurricular interest team" trinity experiment teaching system, forms the teaching characteristics of basic knowledge reinforcement and experimental process are acted as guide, the reforms not only deepen the students' understanding to theoretical knowledge, help them develop the abstract thinking ability, but also enhance the communication fusion between basic knowledge and professional knowledge, cultivate the students' abstract thinking ability, make them understand and master the solution methods of practical engineering, finally, the teaching purpose is achieved.

\section{REFERENCES}

[1] Wang Xueren, Yi Chunan, Ning Chao. The discussion of case teaching methods on "heat transfer theory" in Institutions of higher learning [J]. Power Education in China, 2010, (12):74-75.

[2] Qiu Lin. became the pastor-developer. The application of open and interactive teaching mode in graduate higher heat transfer course teaching [J]. Journal of Higher Building Education, 2008, 17(4):95-97.

[3] Yu Hailong, Ma Min, Yin Guangzhi. The discusses of computer aided teaching in "Industrial Ventilation and Air-conditioning"[J]. HVAC, 1998, 28(5):57-58. 
[4] Chen Shijiang, Zhang Dengchun, Yu Qi. The research of practice teaching in testing technology course of Architectural Environment and Equipment Engineering[J]. Journal of Higher Building Education, 2008, 17(1):118-121.

[5] Luo Qing, Chen Min, Ding Yong. The analysis of the advantages and disadvantages on multimedia teaching in the basis course of Architectural Environment and Equipment Engineering[J]. Journal of Higher Building Education, 2007, 16(5):150-152.

[6] Pan Zhou. The theory and application of situational experience type teaching[J]. Journal of TianJin Vocational Colleges, 2006, 6(8):62-65.
[7] Liu Peng. Several thinking about situational experience teaching[J] GuiHai review, 2010, 6(1):12-15.

[8] Zhang Jinhua, Ye Lei. The research review of situational experience teaching $[\mathrm{J}]$. Journal of Heilongjiang Higher Education Research, 2010, 6:143-145.

[9] Pan Ziyan, Huang Feng. The application of situational experience teaching in employment guidance course[J]. Consumer Guide, 2009, 9:197. 